\title{
Interfaces à transmissão e spillover do coronavírus entre florestas e cidades
}

\author{
ANDRE LUIS ACOSTA, I FERNANDO XAVIER, II \\ LEONARDO SUVEGES MOREIRA CHAVES, ${ }^{\text {III }}$ \\ ESTER CERDEIRA SABINO, ${ }^{I V}$ \\ ANTONIO MAURO SARAIVA ${ }^{V}$ \\ e MARIA ANICE MUREB SALLUMVI
}

\section{Introdução: Covid-19 e o ambiente}

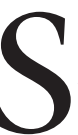

E AS MUDANÇAS climáticas e o desmatamento ainda não convenciam a opinião pública, a pandemia de Covid-19 tem sido bastante tangível em evidenciar que impactos na natureza podem retornar rapidamente em severos prejuízos aos seres humanos. Em poucas semanas o novo coronavírus Sars- CoV-2 se espalhou pelo planeta, usando nossos corpos como meio de dispersão. A pandemia expôs desvantagens da moderna hipermobilidade, evidenciou fragilidades dos sistemas econômicos, dos serviços públicos e privados de saúde e, sobretudo, gerou severos impactos emocionais e psicológicos, além de incontáveis mortos.

A Covid-19 é uma doença de origem zoonótica, portanto o agente infeccioso Sars-CoV-2 é oriundo de animais silvestres, mas adquiriu a capacidade de saltar entre diferentes espécies - incluindo a habilidade de infectar humanos - por meio de processo chamado spillover (Plowright et al., 2017). Estima-se que mais de $60 \%$ de todas as doenças infecciosas humanas já conhecidas e mais de 75\% de outras emergentes serão derivadas de zoonoses (Jones et al., 2008). Quanto maior a proximidade humana com outros animais, maior será a exposição aos agentes infecciosos que circulam enzooticamente neles, aumentando o risco de spillover.

Testes laboratoriais demonstraram que Sars-CoV-2, cepa causadora da Covid-19, tem provável origem em morcegos do gênero Rhinolophus (Benvenuto et al., 2020), similar à origem de outras cepas de coronavírus que também causam doenças humanas: Sars-CoV-1 e Mers-CoV (Wong et al., 2019). Notavelmente, uma das cepas de coronavírus encontrada nesses morcegos apresentou uma sequência genômica (RaTG13) similar em cerca de 90\% àquela encontrada no Sars-CoV-2 (Zhang et al., 2020; Zhou et al., 2020). Embora a similaridade 
não seja muito alta, sugere origem de Sars-CoV-2 a partir de mutações de cepa que originalmente circulava nesses morcegos (Andersen et al., 2020; Benvenuto et al., 2020; Liu et al., 2020).

Pesquisas têm indicado que para o novo coronavírus ser capaz de infectar humanos houve a intermediação de animais silvestres (Benvenuto et al., 2020). Muitas espécies estão sendo investigadas, como serpentes, civetes, visons, até mesmo cães e gatos (Lam et al., 2020). Porém, até o momento, a explicação mais robusta sobre a sequência de eventos que levou ao spillover do novo coronavírus indica dois eventos: o intermédio de espécies silvestres, entre morcegos e pangolins da Malásia (Liu et al., 2020; Xiao et al., 2020) e o modo de exploração da biodiversidade, envolvendo comércio e morte de espécies silvestres.

É bem conhecido entre virologistas que morcegos (Chiroptera) são hospedeiros primários de grande variedade de grupos virais, e por seu sistema imunológico peculiar, lhes causam pouco ou nenhum dano à saúde (Li et al., 2005; Hu et al., 2015; Wong et al., 2019). Enquanto voam, morcegos depositam seus excrementos sobre o solo, prestando serviço essencial na dispersão de sementes; porém, nesse processo os morcegos portadores de coronavírus podem ter contaminado a área onde habitam; locais também utilizados por outras espécies, notavelmente pelos pangolins (gênero Manis; Liu et al., 2020). Esses mamíferos habitam florestas da África subsaariana e da Ásia, e se alimentam de formigas e cupins usando suas imensas unhas para escavar e sua língua pegajosa para capturar os insetos. Frequentemente procuram abrigo em cavidades de rochas, no solo, em troncos ocos e entradas de cavernas, locais também usados pelos morcegos. Esse compartilhamento de hábitat pode ter favorecido o spillover do coronavírus dos morcegos aos pangolins.

Os pangolins são os animais silvestres mais traficados do planeta, e a China tem sido o maior financiador desse tráfico ilegal. Milhões desses animais já foram retirados da natureza para suprir o mercado asiático (IUCN, 20 20). Em plena pandemia (abril de 2020), seis toneladas de escamas de pangolins foram apreendidas por autoridades malaias em um único carregamento (Alberts, 2020 ). Isso acontece porque se acredita que o consumo da carne de pangolim traz efeitos medicinais, e o chá de suas escamas teria algum poder contra a disfunção erétil (BBC-Pangolins, 2020; Bale, 2020). Esse consumo, ou contato de sua carne crua com outros alimentos, tem sido apontado como fatores facilitadores ao spillover da cepa que deu origem a Sars-CoV-2 (Liu et al., 2020). Eventualmente, o consumo da própria carne de morcego portador de coronavírus pode ter sido o fator de exposição que facilitou o spillover. Não obstante a transmissão direta de coronavírus dos morcegos aos humanos possa acontecer, é evento raro e menos provável do que o spillover a partir de outro animal (Plowright et al., 2017).

O "mercado molhado" Huanan na cidade de Wuhan tem sido apontado como marco zero dessa pandemia, pelo fato de lá serem vendidos animais vivos 
em meio ao comércio de frutos do mar, de carnes variadas, incluindo animais silvestres como morcegos, pangolins, roedores e outros potenciais hospedeiros de coronavírus, mas também porque mais da metade das pessoas inicialmente diagnosticadas com Covid-19 estiveram nesse mercado (Huang et al., 2020). Esses hábitos alimentares que estimulam o comércio de animais silvestres têm causado "indigestão" na opinião pública global. Mas, apesar das fortes evidências, até o momento não é possível afirmar que o consumo de animais silvestres tenha iniciado a Covid-19. O que é seguro afirmar é que a nossa forma de explorar a biodiversidade tem sido agressiva e tem provocado diversos problemas à saúde humana. O spillover de patógenos de animais para humanos é apenas uma das formas de repercussão de nossas atividades na natureza, e cenários indicam que, sem mudanças drásticas neste formato de exploração, as epidemias virais poderão se tornar mais frequentes e intensas (Smith et al., 2014).

Mas além do spillover de patógenos da selva para as cidades, a nossa proximidade cada dia maior com hábitats silvestres gera preocupação quanto à possibilidade de invasão do coronavírus nas florestas, partindo dos humanos (Spear et al., 2018). Se considerarmos a quantidade de espécies vulneráveis ao novo coronavírus que o Brasil possui, especialmente a riqueza de morcegos na Amazônia, perceberemos o alto potencial de os biomas brasileiros se tornarem imensos reservatórios; e de lá poderão retornar novas cepas eventualmente ainda mais perigosas à saúde (Jordan; Howard, 2020).

Cada vez mais temos evidências de que a qualidade da saúde humana, dos animais e dos ecossistemas está inexoravelmente interligada. Todavia, ainda há grande dificuldade em se perceber que as atividades humanas mais essenciais geram impactos nos ecossistemas, porque estamos reféns de um modelo obsoleto de desenvolvimento, em que o capital econômico é construído em detrimento do capital natural (Costanza, 2020).

Apesar de ser razoavelmente seguro afirmar que muitas pessoas nunca se alimentaram de animais silvestres, será difícil encontrar quem nunca consumiu o óleo de palma, usado em diversos produtos. Ou nunca tenha consumido soja - de cujas sementes se extraem óleo, farinha, proteína e "leite". Ou ainda, não se beneficiado de produtos oriundos da cana-de-açúcar - da qual se extraem combustível, alimentos, bebidas, adoçante, e até o álcool em gel que usamos contra o coronavírus. Essas plantações estão entre os maiores fatores indutores de destruição e fragmentação de hábitats florestais no mundo. Com elas, a pecuária - que transforma os solos em pastagens para que tenhamos laticínios e carnes. Além disso, temos a desflorestação para obtenção de lenha e madeira; a degradação pela mineração e suas barragens de rejeitos. Tudo isso sem contar as atividades ilegais, como invasões de terra por grileiros, posseiros e garimpeiros, entre tantas outras.

Portanto, de forma deliberada ou não, todos estamos envolvidos na geração de impactos à natureza. Mas, inquestionavelmente, temos que continuar 
a produzir alimentos, matéria-prima, energia. Na verdade, temos que aumentar a produção, pois a população humana não para de crescer. Mas existem formas ambientalmente amigáveis de se fazer tudo isso, e conhecimentos científicos para tornar sustentáveis os setores produtivos. Embora grande esforço seja exigido, um novo mindset é urgente, bem como colocar os procedimentos de produção sustentável em prática (Costanza, 2020; Wirén-Lehr, 2001).

Em tempos de crise, nossas necessidades mais prementes tornam-se evidentes. Deveríamos aproveitar esses momentos para revisar prioridades e refletir sobre decisões individuais e coletivas que têm repercutido na forma de prejuízos. Por isso, torna-se um importante exercício pensar que, se animais selvagens não fossem explorados, a cepa do coronavírus que evoluiu para Sars-CoV-2 poderia ter permanecido limitada às fronteiras das florestas, circulando enzooticamente entre animais silvestres, e a humanidade poderia não sofrer a Covid-19.

Este artigo aborda aspectos das atividades humanas que afetam o ambiente e podem influenciar na transmissão e spillover de coronavírus entre os animais silvestres, e deles aos humanos e aos animais em ambientes antrópicos. Mas também os riscos de o coronavírus retornar da cidade para a selva, e lá se modificar, em preparação para um novo retorno pandêmico.

\section{O coronavírus nas pandemias deste milênio}

Neste início de milênio já há registros de ao menos 66 grandes eventos epidêmicos (lista de Epidemias, 2020), a vasta maioria dos casos por dengue, cólera e ebola, ocorrendo predominantemente em países africanos e asiáticos. Nas duas primeiras décadas, destacam-se seis grandes pandemias que geraram alto número de mortes: (1) Em 2002, a Sars-CoV-1 na China, espalhando-se por 29 países e contaminando mais de oito mil pessoas, levando à morte cerca de 800 ; (2) Em 2009, a Influenza H1N1 que espalhou-se por 214 países contaminando bilhões, estima-se ter causado mais de 200 mil mortes; (3) Em 2012, a Síndrome Respiratória do Oriente Médio (Mers-CoV) na Arábia Saudita, espalhando por 24 países e contaminando mais de 2.500 pessoas, com 862 mortes registradas; (4) Em 2013, uma grande epidemia de ebola ocorreu no oeste africano, espalhando-se por dez países e contaminando mais de 28 mil pessoas e gerando 11 mil mortes; (5) Em 2015, o início da zika foi percebido pelo aumento drástico de casos de microcefalia em recém-nascidos, com casos de transmissão em 87 países (who-Diseases, 2020). Só no Brasil, 3.474 casos foram confirmados com 402 óbitos fetais e neonatais associados (MS-ZKV, 2020); (6) E em novembro 2019 inicia-se a terceira epidemia de coronavírus: a Covid-19. Tornando-se a maior e pior epidemia de coronavírus da história humana, e a mais mortal dos últimos cem anos. Expandiu-se por praticamente toda a superfície terrestre habitada, exceto dez pequenas ilhas e a ausência de registros de dois países continentais (McCarthy, 2020).

A Covid-19 está em plena expansão, e ainda poderá levar muitos meses ou anos para ser controlada. Cenários mais otimistas sugerem que o número 
de mortos ao longo de toda epidemia não ultrapassará um milhão (BBC-News, 2020); já cenários de inação contra a doença sugerem a possibilidade de mortes na ordem de 40 milhões (Graham et al., 2020); e os mais pessimistas estimam números maiores que 100 milhões (EIU, 2020; Rajgor et al., 2020). Se o cenário mais pessimista se realizar, a Covid-19 estará entre as piores pandemias da história humana, junto com a peste negra (1346-1353; 75-200 milhões), a praga justiniana (541-542; 25 milhões) e a gripe espanhola (1918-1920; 20-50 milhões).

A família Coronaviridae possui quatro gêneros ( $\alpha, \beta, \gamma$ e $\delta$-coronavirus), mas apenas o alfa e o betacoronavírus causam doenças humanas por meio de sete cepas virais, das quais quatro causam doenças há muito tempo na humanidade, mas atualmente resultam em apenas sintomas leves (Corman et al., 2018). Entretanto, três cepas mais recentes causam doenças graves e alta mortalidade: a Mers-CoV; a Sars-CoV-1; e, agora, a Sars-CoV-2.

A cepa Sars-CoV-1 é causadora da doença Severe Acute Respiratory Syndrome (Sars), e as pesquisas indicaram que transbordou do morcego a um pequeno mamífero silvestre, a civeta (Paguma larvata), e delas para os humanos. No caso da Middle East Respiratory Syndrome (Mers), que é a forma mais letal de doença humana por coronavírus, o camelo foi apontado como hospedeiro intermediário que transbordou coronavírus aos humanos (Mers-CoV) também a partir de cepa de morcegos. Tanto na epidemia de Sars (Sars-CoV-1) como na Covid-19 (Sars-CoV-2), o comércio ilegal e o consumo de animais silvestres estão associados aos fatores que as desencadearam.

Ainda há grande discussão sobre o papel do pangolim como hospedeiro intermediário na transmissão de coronavírus aos humanos, mas ainda não há explicação alternativa mais robusta ou evidências refutando esta hipótese (Zhang et al., 2020; Xiao et al., 2020). A similaridade genética total entre Sars-CoV-2 e cepa viral identificada no pangolim (Pangolim-CoV) é de 90,3\%, valor que pode ser considerado alto, mas não determinante (Cyranoski, 2020). O que se tem segurança para afirmar até o momento é que todas as pandemias de coronavírus tiveram origem zoonótica de morcegos e aconteceram nos últimos vinte anos, representando metade das maiores e mais letais pandemias do milênio. Existe aparente processo de consolidação da circulação de cepas de coronavírus na sociedade humana, e o grande alcance da Covid-19 está gerando o risco de torná-la endêmica.

\section{Interfaces entre floresta e cidade}

Por muito tempo, a ação humana mais impactante no ambiente tem sido a mudança na cobertura dos solos (Newbold et al., 2015). Nesse processo, que envolve total supressão e queima da vegetação, a maioria das espécies vegetais, animais sésseis e com reduzida mobilidade (ex.: moluscos, artrópodes, anfíbios) é exterminada rapidamente; e as espécies altamente móveis (ex.: mamíferos, aves) que não foram incineradas fogem, abandonando recursos alimentares, abrigos e crias (Tilman et al., 2001; Turner, 2010). 
Com a eliminação dos seus nichos efetivos, os animais - geralmente espécies de topo das cadeias alimentares - são obrigados a se dispersar em busca de refúgios na extensão de seu nicho fundamental, onde existem recursos e condições disponíveis à sobrevivência (Soberón; Nakamura, 2009). Entretanto, essas são áreas que já estão ocupadas com biodiversidade, levando-os aos impactos decorrentes da intensificação da competição, da predação e da superexploração de recursos (Burdon et al., 2019; Layman et al., 2007). Nesses refúgios, há aumento repentino de abundância e riqueza de espécies, maximizando o contato entre os organismos, elevando a probabilidade de transmissão e circulação de parasitos dentro da população, mas também de spillover entre espécies (Wilkinson et al., 2018). Em ambiente espacialmente limitado e "comprimido de indivíduos e espécies", o processo de transmissão viral é facilitado e pode ocorrer por meio de interações diretas, notavelmente por predação e conflitos entre indivíduos, relações sexuais, comportamentais e sociais, e agrupamentos noturnos ou compartilhamento de abrigos. De forma indireta, poderá ocorrer pelo contato com urina e fezes contaminadas no compartilhamento de hábitat, pelo contato com saliva e muco durante o compartilhamento de recursos alimentares, ou pelo contato com sangue e restos de animais predados (Plowright et al., 2017; Jofrin et al., 2018).

Em um ambiente com alta sobreposição de hábitats, os recursos compartilhados entre espécies tornam-se superexplorados, aproximando os indivíduos e intensificando os riscos de spillover (Plowright et al., 2017). Nesse contexto, por exemplo, um tronco oco de árvore onde apenas uma família de pangolins abrigava-se torna-se um recurso escasso e altamente demandado, e passa a ser compartilhado também por famílias de morcegos e roedores. Na parte superior do oco penduram-se os morcegos, na linha do solo estão os pangolins, e a baixo deles, no subterrâneo, vivem os roedores. Nesse local os riscos de spillover de coronavírus são potencializados por uma sequência de contatos de cima abaixo, desde as fezes e urina dos morcegos caindo sobre os pangolins e, na sequência, de ambos sobre os roedores.

No modelo de uso dos solos em que há conversão integral das áreas naturais, criam-se zonas transicionais abruptas entre ambientes silvestres e matriz antrópica (plantações, áreas urbanas). Nessa transição forma-se um cinturão marginal contornando os fragmentos remanescentes, atuando como ecótono, mas sob influência do "efeito de borda". Existe um produtivo debate sobre as repercussões ecológicas do "efeito de borda" e da tipologia de fragmentação nas paisagens, a variar com a configuração, composição e tamanho dos fragmentos (Fletcher et al., 2018; Fahrig et al., 2019). Mas, de uma forma geral, autores consideram que bordas transicionais largas resultam em maior probabilidade de spillover em paisagens altamente fragmentadas; portanto, maiores riscos de spillover de patógenos. Outros declaram que as bordas, por se comportarem como ecótonos, apresentam alta diversidade, pois são interfaces usadas por espécies oriundas de variados 
tipos de ambientes; portanto, nessa faixa haveria potencial também para uma maior diversidade viral, aumentando o risco de spillover. Muitos argumentam que nessas margens predominam as espécies generalistas, pois são capazes de explorar recursos variados em diferentes ambientes; portanto, teriam maior facilidade para circular entre diferentes hábitats, podendo atuar como vetor de vírus entre zonas silvestres e antrópicas, e vice-versa (Patz et al., 2004; Ries et al., 2004; Plowright et al., 2017; Wilkinson et al., 2018; Zohdy et al., 2019).

Para todos os efeitos, a conversão dos solos e a fragmentação dos hábitats geram zonas de maior contato, viabilizando novas interfaces entre os hábitats naturais e os ambientes antrópicos, promovendo interações interespecíficas, e aproximando reservatórios, vetores e hospedeiros, aumentando as possibilidades de transmissão e spillover viral (Ries et al., 2004; Patz et al., 2004; Wilkinson et al., 2018). Tem-se demonstrado que a fragmentação atua em conjunto com "efeitos coevolutivos", aumentando a diversificação de vírus em ambientes silvestres, o que poderia favorecer a emergência de novas cepas (Zohdy et al., 2019). Existem evidências associando alterações de paisagens com emergência de doenças como malária, hantavirose, filariose, febres hemorrágicas, e muitas outras (Patz et al., 2004). Mas, no que concerne aos potenciais impactos do coronavírus à biodiversidade brasileira, a possibilidade de o humano atuar como vetor de coronavírus para outros animais gera um cenário epidemiológico assustador: um alerta para o futuro.

\section{Fauna urbana, doméstica e tráfico de animais silvestres}

Cepas de coronavírus já foram identificadas em diversas espécies de animais, como tigres, leões, chimpanzés, esquilos, furões, gambás, cachorros, gatos e cavalos. Mas quando se trata de morcegos, coronavírus foram detectados em diferentes gêneros (Hipposideros; Taphozous; Mystacina; Rousettus), mas especialmente em morcegos do gênero Rhinolophus ( $R$. affinis, $R$. macrotis, $R$. ferrumequinum, $R$. pearsoni, $R$. sinicus, $R$. pussilus, $R$. hipposideros) Li et al., 2005; Zhou et al., 2020; Andersen et al., 2020). Peculiarmente, coronavírus é capaz de transbordar para uma grande variedade de mamíferos, porém, aparentemente, não para as aves, répteis, peixes e (possivelmente) anfíbios (Lam et al., 2020).

É razoável sugerir que espécies proximamente aparentadas com organismos já contaminados por coronavírus possam ser susceptíveis (Guan et al., 2003; Lam et al., 2020). Mas o processo de rompimento de barreiras interespecíficas para ocorrência de spillover não é simples, múltiplos fatores precisam estar alinhados (Plowright et al., 2017). Mesmo assim, acontece o tempo todo na natureza, e faz parte do processo evolutivo das espécies. Para se ter ideia, cerca de $8 \%$ do genoma humano consistem de fragmentos retrovirais, e parte deles são remanescentes de processos seletivos impostos por doenças epidêmicas do passado (Subramanian et al., 2011). Portanto, saltos de coronavírus para novas espécies continuarão a acontecer, e a frequência de spillover irá depender da proximidade entre indivíduos susceptíveis e contaminados (Plowright et al., 2017; 
Spear et al., 2018). Embora o coronavírus possa saltar diretamente de morcegos para humanos, a probabilidade é considerada baixa, especialmente em relação ao alto potencial de spillover de coronavírus entre espécies selvagens, notavelmente entre espécies de morcegos (Hu et al., 2015; Li et al., 2019).

Também há grande preocupação quanto à reversão do spillover de Sars-CoV-2, partindo dos humanos em direção às espécies silvestres (Lam et al., 2020). Sabemos que o coronavírus chegou ao Brasil "por meio dos aviões", e até o momento circula apenas nos ambientes antrópicos. Mas existe o risco de Sars-CoV-2 saltar de humanos para hospedeiros intermediários que transitam entre ambientes antrópicos e silvestres, como pequenos primatas, morcegos e outros mamíferos, levando o coronavírus para as espécies selvagens (Lam et al., 2020). Esse processo poderia levar ao endemismo e circulação zoonótica do coronavírus em ambiente silvestre, que após processos de mutação e recombinação viral, poderia retornar (spillback) do ambiente silvestre para o antrópico como nova cepa, eventualmente se manifestando como uma nova doença parecida com a Covid-19, ou mais letal, como Sars e Mers.

Pela proximidade genética com humanos, conservacionistas e primatologistas têm manifestado preocupação com a vulnerabilidade dos grandes símios, como gorilas, chimpanzés e orangotangos, perante a alta possibilidade de spillover de Sars-CoV-2 a partir dos humanos, o que poderá dizimar espécimes em zoológicos e populações selvagens inteiras (Patrono et al., 2018; Gillespie; Leendertz, 2020). Embora em nossos biomas não haja grandes símios, com 118 espécies registradas, o Brasil é o país com a maior riqueza de primatas no mundo (Paglia et al., 2012). Assim, essa preocupação com relação à alta susceptibilidade de primatas em contrair Sars-CoV-2 também se aplica às nossas espécies. Alguns primatas brasileiros, como saguis e macacos-pregos, habitualmente circulam do interior para as margens de florestas, onde frequentemente interagem com humanos. Inclusive, em zonas altamente habitadas como a Região Metropolitana da cidade de São Paulo, saguis podem ser vistos circulando em condomínios residenciais, sendo alimentados por crianças e interagindo com animais domésticos. Na possibilidade de spillover de coronavírus entre primatas, esses aspectos ressaltam o risco de atuarem como vetores de duplo sentido, levando o vírus do ambiente antrópico para o silvestre, mas também trazendo-os de volta, em forma de novas cepas.

Outro grupo com espécies que circula entre ambientes silvestres e antrópicos é o dos morcegos. No Brasil, estimam-se existir pelo menos 167 espécies de morcegos, e mais de 30 espécies silvestres já foram registradas habitando áreas urbanas, e cerca de 40 delas vivendo em zonas periurbanas (Pacheco et al., 2010; Bernard et al., 2011). Segundo pesquisadores, registros entre 60 e 90 espécies de morcegos vivendo uma única localidade na zona neotropical não são raros de se encontrar, enfatizando o alto risco de spillover de coronavírus entre diferentes espécies de morcegos da fauna brasileira (Bernard et al., 2011). 
Em zonas urbanas, morcegos costumam nidificar em forros de casas, onde também se encontram lagartixas, pombos, ratos, até mesmo marsupiais, os gambás (Valadas et al., 2016). Portanto, são espécies em estreita proximidade, inclusive com humanos, aumentando risco de contato com secreções, além da contaminação de utensílios e alimentos consumidos por humanos e de animais domésticos. Tantos os gambás quanto os ratos costumam revirar lixeiras, as quais podem ter resíduos contaminados com Sars-CoV-2. Portanto, uma rede de possibilidades de spillover emerge nas múltiplas interações entre mamíferos e humanos e ambiente antrópico.

Em zonas periurbanas e rurais, roedores e morcegos compartilham galpões onde se armazenam alimentos, grãos e se criam animais. Em forros e nas estruturas de teto das granjas é comum encontrarem-se ninhos e morcegos pendurados, cujos dejetos precipitam sobre os animais e seus alimentos. Também nas estruturas dos chiqueiros e dos currais, roedores e morcegos encontram local para nidificação, mas esses locais também armazenam os recursos alimentares explorados por morcegos hematófagos, como vacas, porcos e cavalos. Todas as três espécies de morcegos hematófagos se distribuem pelo Brasil (Diaemus youngii, Diphylla ecaudata e Desmodus rotundus; Santos et al., 2007). Considerando-se que a Amazônia possui a maior diversidade de morcegos (146 sp) e de primatas (94 sp) dos biomas brasileiros (Bernard et al., 201 1; Paglia et al., 2012), a interiorização de Sars-CoV-2 no ambiente silvestre poderia tornar esse bioma o maior reservatório de coronavírus do planeta, gerando-se um cenário assustador para a biodiversidade e a humanidade.

A predação atua no controle populacional das espécies, de forma que a demanda por recursos esteja ajustada à oferta. Em populações muito abundantes, a susceptibilidade à emergência de doenças infecciosas é aumentada. Portanto, no prisma epidemiológico, os predadores agem em favor de suas presas quando regulam suas populações, pois também reduzem o potencial de emergência de patógenos na população (Holt; Roy, 2007). Dessa forma, se o coronavírus eliminar espécies silvestres do topo das cadeias tróficas (predadores), poderá haver aumento populacional de presas, o que poderá influenciar na emergência de outras doenças infecciosas.

Todos os biomas brasileiros sofrem com exploração ilegal e tráfico de animais silvestres, que estão entre os principais fatores de perda de biodiversidade no país. Nessas atividades, pessoas circulam das cidades ao interior dos ambientes silvestres, e poderão dispersar consigo a cepa de Sars-CoV-2. No contexto do coronavírus, além dos impactos que causam à vida silvestre, a caça poderá trazer ainda maiores riscos à saúde, considerando que os caçadores miram especialmente em mamíferos como paca, capivara, tatu e tamanduá (Constantino, 2018; Bragagnolo et al., 2019). Todas espécies potencialmente susceptíveis a Sars-CoV-2, especialmente os Xenartros (tamanduás, tatus e preguiças), parentes (filogeneticamente) próximos dos pangolins (Pholidotamorpha), ressaltando 
a possibilidade de caçadores agirem como potenciais vetores de coronavírus; e nesse sentido, também se incluem garimpeiros, madeireiros, posseiros, e pessoas cujas atividades envolvam circular entre zonas nucleares de florestas e cidades.

\section{A saúde planetária no pós-Covid-19}

Nesse momento, a sociedade humana está "fora dos trilhos". Naturalmente, a Covid-19 irá predominar na atenção pública, colocando em "stand by" problemas outrora primários. Mas, como toda pandemia na história humana, irá tornar-se passado, embora não se possa afirmar que será superada, pois está deixando profundas cicatrizes nas gerações atuais, com reflexos que ecoarão por muitas gerações. Em termos de agenda de governança, deixar problemas globais se acumularem não é uma boa estratégia, pois tendem a agravar-se seriamente com o tempo, culminando em colapsos, como a própria Covid-19.

Um dos problemas prioritários é o tamanho da população humana, que continua a crescer rapidamente; estima-se alcançar 9,8 bilhões em 2050. Para suprir a crescente demanda, a produção alimentar deverá ser aumentada em pelo menos 60\% e a disponibilidade de água, em 40\% (UN, 2015). Entretanto, mais de um terço da superfície terrestre e 75\% dos recursos de água doce já estão dedicados à agropecuária (IPBES, 2018). Não é sem razão que cerca de $70 \%$ da população global já apresentam algum nível de dificuldade no acesso à água doce, e 66\% sofrem com a escassez (Mekonnen; Hoekstra, 2016). Para assegurar a disponibilidade da água deve-se conservar ecossistemas florestais, pois mais de $75 \%$ de toda água doce são oriundos de suas bacias hidrográficas (FAO, 2020). Mesmo assim, 3,6 milhões de hectares de florestas são perdidos anualmente, e durante a pandemia, o desmatamento na Amazônia volta a aumentar, 51\% em relação a 2019, é o nível mais alto no período desde 2016 (Weisse; Goldman, 2019; Barifouse, 2020).

Já ultrapassamos alguns limites planetários, dois deles por causas intimamente associadas à produção alimentar, que são as emissões ambientais de fósforo e nitrogênio (Sterner et al., 2019). Além desses nutrientes, há o massivo despejo de resíduos de origem animal e vegetal (matéria fecal de criações, vinhoto da cana-de-açúcar) sobre os solos e corpos d'água, eutrofizando e alterando a microbiota. Em conjunto, a excessiva dispersão de agrotóxicos sobre plantas agrícolas (inseticidas, fungicidas), colateralmente atingindo as plantas silvestres em áreas adjacentes, atacando a biodiversidade nativa de insetos, inclusive polinizadores, predadores de pragas e outros importantes prestadores de serviços ecossistêmicos (Foley et al., 2005). Outro limite altamente excedido é o da taxa de extinção de espécies, alimentada pela perda de hábitat e com forte contribuição da produção agrícola e pecuária (SRC, 2015). A biodiversidade tem papel fundamental no provimento de serviços ecossistêmicos, os quais beneficiam a produção alimentar e a saúde (ex.: polinização, ciclagem de água, controle de doenças).

Outra questão primária à saúde é a alteração climática, que atua nas doenças e nas epidemias por diversos mecanismos (Araújo; Naimi, 2020; Baker 
et al., 2020). Muitas doenças virais são sazonais, pois estão associadas às peculiaridades das estações (umidade no ar, variação de temperatura, frequência de chuvas). Variações desfavoráveis (ar seco, frio) afetam o sistema imunológico dos humanos, e o nível de contato entre humanos, modulando infecções fúngicas, bacterianas e virais, bem como os processos epidêmicos. As mudanças climáticas alteram a expressão dos padrões atmosféricos das estações, podendo deslocar e até aumentar períodos com condições climaticamente favoráveis às infecções. O clima é fator primário aos nichos ecológicos, determinando as áreas das distribuições das espécies. Alterações climáticas degradam a adequabilidade dos hábitats, que em certas situações obrigam as espécies a se dispersarem para novas localidades. $\mathrm{O}$ vírus, pela sua condição de parasita obrigatório, se dispersa junto com as espécies, levando e elevando o risco de spillover para novas áreas e para outras espécies.

Um dos maiores desafios da humanidade no futuro é aumentar a produção e distribuição de alimentos e água potável. E outro é frear a perda e fragmentação dos hábitats silvestres em favor da conservação da biodiversidade e dos ecossistemas. No formato de desenvolvimento vigente, o suprimento das demandas nutricionais humanas aparenta antagonizar com os meios para a conservação dos ecossistemas, gerando um paradoxo: "O bem-estar, a saúde e a prosperidade da sociedade humana estariam inexoravelmente atrelados ao incremento da degradação ambiental?" (Raudsepp-Hearne et al., 2010). Nesse quesito, o conceito de Saúde Planetária (Whitmee et al., 2015) aponta para alternativas viáveis, pois a própria viabilidade das alternativas estão sendo consideradas na formulação de soluções. E mais do que encontrar meios para equilibrar a balança entre saúde humana e saúde ambiental, o conceito na prática deverá habilitar a capacidade humana de perceber que essa dualidade equivocada. Só há um único aspecto a ser tratado, que é a saúde do planeta, na qual a saúde humana, animal e ambiental é componente intrínseco e indissociável.

Soluções para produção alimentar sustentável já estão ao nosso alcance, e estão alinhadas com uma nova definição de produtividade, em que também se contabilize a qualidade de vida de quem produz, de quem consome e a qualidade do ambiente onde se produz. Certamente será um grande esforço, que envolverá a dedicação de gerações, mas normalmente, mudanças de longo alcance na sociedade humana surgem a partir de grandes impactos, assim a Covid-19 se apresenta como um ensejo e uma oportunidade.

\section{Conclusões}

Pelo fato de epidemias como a Covid-19 estarem associadas à forma que desenvolvemos nossas atividades denota que os humanos têm o poder para modificar tendências, evitando a emergência de eventos futuros. Portanto, ao invés de se desejar "voltar aos trilhos" da antiga trajetória, a sociedade humana poderia desejar e trabalhar para construir um novo caminho, direcionando-se para um modelo sustentável. Até o momento, estivemos focados em ganhos e 
vantagens imediatas; eventualmente, nossa percepção de presente e de futuro se aprimore após a Covid-19, e passemos a investir nossos esforços pensando em longo prazo, em ter qualidade de vida agora, mas também deixar um melhor legado às futuras gerações. Esse esforço exigirá que as sociedades promovam novos padrões de consumo, novos conceitos de autorrealização, e uma totalmente nova percepção de relação entre humanos, e deles com o ambiente. A aplicação do conceito de saúde planetária viabiliza meios para um novo modelo de desenvolvimento, um em que as tendências mais marcantes sejam impulsionadas por forças da equidade, do equilíbrio e da eficiência, construídas com respeito pela integridade dos sistemas naturais, pela ética no convívio entre pessoas e, sobretudo, com a percepção de que o planeta e todos seus componentes - seres e sistemas - são inexoravelmente interconectados e compartilham destino comum.

Agradecimento - André Luis Acosta agradece o suporte da Fapesp (PF: 2019/129887).

\section{Referências}

ALBERTS, E. C. Malaysian authorities seize record 6 tons of African pangolin scales. MONGABAY, 7 abr. 2020. Disponível em: <https://bit.ly/3eixRIS>. Acesso em: maio 2020 .

ANDERSEN, K. G. et al. The Proximal Origin of SARS-CoV-2. Nature Med., v.26, 2020.

ARAUJO, M. B; NAIMI, B. Spread of SARS-CoV-2 Coronavirus likely to be constrained by climate. Cold Spring Harbor Laboratory, 2020.

BAKER, R. E. et al. Susceptible Supply Limits the Role of Climate in the Early SARS-CoV-2 Pandemic. Science, 2020.

BALE, R. Trafficked pangolins can carry coronaviruses closely related to pandemic strain. NatGeo, 2020. Disponível em: <https://on.natgeo.com/3d06KIB>. Acesso: maio 2020.

BARIFOUSE, R. Pandemia vai permitir aceleração do desmatamento na Amazônia, prevê consultoria. BBC, 2020. Disponível em: <https://bbc.in/2TAbpco>. Acesso em: maio 2020.

BBC-NEWS. Coronavírus pode ser só ensaio de uma próxima grande pandemia, diz médico e matemático da USP. BBC News, 5 maio 2020. Disponível em: <https://bbc. in/3eluCGZ>. Acesso em: maio 2020.

BBC-PANGOLINS. Pangolins: The World's Most Wanted Animals. BBC 2020. Disponível em: <https://bbc.in/2Tz96GF>. Acesso em: maio 2020.

BENVENUTO, D. et al. The 2019 new Coronavirus Epidemic: Evidence for Virus Evolution. J. of Med. Virology, v.92, 2020.

BERNARD, E. et al. Compilação atualizada das espécies de morcegos (Chiroptera) para a Amazônia Brasileira. Biota Neotropica, v.1, 2011. 
BRAGAgNOLO, C. et al. Hunting in Brazil: What Are the Options? Persp. Ecol. \& Conserv., v.17, p.71, 2019.

BURDON, F. J. et al. Mechanisms of Trophic Niche Compression: Evidence from Landscape Disturbance. J. of An. Ecology, v.89, 2019.

CONSTANTINO, P. A. L. O perfil da caça nos biomas brasileiros: um Panorama das Unidades de Conservação Federais a partir dos autos de infração lavrados pelo ICMBio. Biodiversidade Brasileira, v.8, n.2, p.106-129, 2018.

COSTANZA, R. Valuing Natural Capital and Ecosystem Services toward the Goals of Efficiency, Fairness, and Sustainability. Eco. Services, v.43, 2020.

CORMAN, V. M. et al. Hosts and Sources of Endemic Human Coronaviruses. In: Adv. in Virus Research. 2018.

CYRANOSKI, D. Mystery Deepens over Animal Source of Coronavirus. Nature, v.579, 2020.

DHAMA, K. et al. SARS-CoV-2: Jumping the Species Barrier, Lessons from SARS and MERS, Its Zoonotic Spillover, Transmission to Humans, Preventive and Control Measures. MDPI AG, 2020.

EIU. Covid19-What to expect in 2021-22. The Economist Intelligence Unit. 2020. Disponível em: <https://bit.ly/2LYLzdO>. Acesso em: maio 2020.

FAHRIG, L. et al. Is Habitat Fragmentation Bad for Biodiversity? Biological Conservation, v.230, 2019.

FAN, Y. et al. Bat Coronaviruses in China. Viruses, v.11, 2019.

FAO. IN: Watershed management - Forestry Communication Toolkit. 2020 Disponível em: <https://bit.ly/36ts6vC>. Acesso em: abril 2020.

FLETCHER, R. J. et al. Is Habitat Fragmentation Good for Biodiversity? Biol.Conserv., v.226, 2018.

FOLEY, J. A. et al. Global Consequences of Land Use. Science, v.309, 2005.

FUENTES, A. Human Niche, Human Behaviour, Human Nature. Interface Focus, v.7, 2017.

GILLESPIE, T. R.; LEENDERTZ, F. H. COVID-19: Protect Great Apes during Human Pandemics. Nature, v.579, 2020.

GRAHAM, F. et al. Daily briefing: Coronavirus could have killed 40 million people if the world had not taken action. Nature Briefing, 2020. Disponível em: <https:// go.nature.com/3dlb4qO>. Acesso em: maio 2020.

GUAN, Y. Isolation and Characterization of Viruses Related to the SARS Coronavirus from Animals in Southern China. Science, v.302, 2003.

HOLT, R. D.; ROY, M. Predation Can Increase the Prevalence of Infectious Disease. The Am. Naturalist, v.169, 2007.

HU, B. et al. Bat Origin of Human Coronaviruses. Virology J., v.12, 2015.

HUANG, C. et al. Clinical Features of Patients Infected with 2019 Novel Coronavirus in Wuhan, China. The Lancet, v.395, 2020.

IPBES. Media Release: Nature's Dangerous Decline Unprecedented Species Extinction 
Rates Accelerating. 2018. Disponível em: <https://bit.ly/36s3bby>. Acesso em: maio 2020 .

IUCN. The status, trade and conservation of Pangolins. CDB-CoP17, 2020. Disponível em: <https://bit.ly/2AluZYn>. Acesso em: maio 2020.

JOFFRIN, L. et al. Bat Pathogens Hit the Road: But Which One? PLOS Pathogens, v.14, 2018.

JONES, K. E. et al. Global Trends in Emerging Infectious Diseases. Nature, v.451, 2008.

JORDAN, L; HOWARD, E. Breaking down the Amazon: how deforestation could drive the next pandemic. Greenpeace, 2020. Disponível em: <https://bit.ly/2XpaxZj>. Acesso em: maio 2020.

LAM, S. et al. SARS-CoV-2 spike protein predicted to form stable complexes with host receptor protein orthologs from mammals. Cold Spring Harbor Lab., 2020.

LAYMAN, C. A. et al. Niche Width Collapse in a Resilient Top Predator Following Ecosystem Fragmentation. Ecol. Letters, v.10, 2007.

LI, H. et al. Human-Animal Interactions and Bat Coronavirus Spillover Potential among Rural Residents in Southern China. Biosafety and Health, v.1, 2019.

LI, W. et al. Bats Are Natural Reservoirs of SARS-Like Coronaviruses. Science, v.310, 2005.

LISTA DE EPIDEMIAS. In: WIKIPÉDIA, a enciclopédia livre. Wikimedia Foundation, 2020. Disponível em: <https://bit.ly/2XupgSG>. Acesso em: maio 2020.

LIU, P. et al. Are pangolins the intermediate host of the 2019 novel coronavirus? Cold Spring Harbor Laboratory, 2020.

MCCARTHY, N. Which Countries Have Escaped The Coronavirus So Far? Statista, 2020. Disponível em: <https://bit.ly/3gmUZ14>. Acesso em: maio 2020.

MEKONNEN, M. M.; HOEKSTRA, A. Y. Four Billion People Facing Severe Water Scarcity. Science Advances, v.2, 2016.

MS-ZKV. Síndrome congênita associada à infecção pelo vírus Zika. S. 1.: Ministério da Saúde, 2019. Disp. <https://bit.ly/3c5FNlC>. Acesso: maio 2020.

NEWBOLD, T. et al. Global Effects of Land Use on Local Terrestrial Biodiversity. Nature, v.520, 2015.

PACHECO, S.M., et al. Morcegos Urbanos: Status do Conhecimento e Plano de Ação para a Conservação no Brasil. Chiroptera Neotropical 16(1), 2010.

PAGLIA, A. P. et al. Lista anotada dos mamíferos do Brasil. 2.ed. Occ. P. Cons. Biol., v.6, 2012. Disponível em: <https://bit.ly/3efDhKM>. Acesso em: maio 2020.

PATRONO, L. V. et al. Human Coronavirus OC43 Outbreak in Wild Chimpanzees, Côte d'Ivoire, 2016. Microbes \& Infections, v.7, 2018.

PATZ, J. A. et al. Unhealthy Landscapes: Policy Recommendations on Land Use Change and Infectious Disease Emergence. Env. H. Perspec., v.12, 2004.

PLOWRIGHT, R. K. et al. Pathways to Zoonotic Spillover. Nature Reviews Microbiology, v.15, 2017. 
RAJGOR, D. D. et al. The Many Estimates of the COVID-19 Case Fatality Rate. The Lancet Infectious Diseases, 2020.

RAUDSEPP-HEARNE, C. et al. Ecosystem Service Bundles for Analyzing Tradeoffs in Diverse Landscapes. PNAS, v.107, 2010.

RIES, L. et al. Ecological Responses to Habitat Edges: Mechanisms, Models, and Variability Explained. Ann. Rev. Ecol. Evol. \& Syst, v.35, 2004.

ROCKSTRÖM, J. et al. A Safe Operating Space for Humanity. Nature, v.461, 2009.

SANTOS, C. F. M. et al. Os quirópteros do Novo Mundo: a América e o morcego hematófago no relato de viajantes quinhentistas. Varia Historia, v.23, 2007.

SMITH, K. F. et al. Global Rise in Human Infectious Disease Outbreaks. J. The Royal Society Interface, v.11, 2014.

SOBERON, J.; NAKAMURA, M. Niches and Distributional Areas: Concepts, Methods, and Assumptions. PNAS, v.106, 2009.

SPEAR, J. E. et al. Ecological Spillover Dynamics of Organisms from Urban to Natural Landscapes. J. Urb. Ecology, v.4, 2018.

SRC. Stockholm Resilience Centre: Planetary Boundaries Interactive Map. 2015. Disponível em: <http://www.anthropocene.info/planetary-boundaries.php>. Acesseo em: abr. 2020.

STERNER, T. et al. Policy Design for the Anthropocene. Nature Sustainability, v.2, 2019.

SUBRAMANIAN, R. P. et al. Identification, Characterization, and Comparative Genomic Distribution of the HERV-K (HML-2). Retrovirology, v.8, 2011.

TILMAN, D. et al. Forecasting Agriculturally Driven Global Environmental Change. Science, v.292, 2001.

TURNER, M. G. Disturbance and Landscape Dynamics in a Changing World. Ecology, v.91, n.10, 2010.

UN. Radical shift in agriculture critical to making future food systems smarter, more efficient - UNO-NEWS, 2015,

VALADAS, S. Y. O. B. et al. A review of Sarcocystis spp. shed by opossums (Didelphis spp.) in Brazil. Brazilian Journal of Veterinary Research and Animal Science, v.53, 2016.

VON WIRÉN-LEHR, S. Sustainability in Agriculture. Agric. Eco. \& Environ, v.84, 2001 .

WEISSE, M.; GOLDMAN, E. D. The World Lost a Belgium-sized Area of Primary Rainforests Last Year. World Resources Institute. 2019. Disponível em: <https://bit. ly/2LUgoRl>. Acesso em: maio 2020.

WHITMEE, S. et al. Safeguarding Human Health in the Anthropocene Epoch: Report of The Rockefeller Foundation-Lancet Commission on Planetary Health. The Lancet, v.386, 2015.

WHO-DISEASES. Emergencies preparedness. World Health Organization, 2020. Disponível em: <https://www.who.int/csr/don/archive/disease/en/>. Acesso em: maio 2020 . 
WILKINSON, D. A. et al. Habitat Fragmentation, Biodiversity Loss and the Risk of Novel Infectious Disease Emergence. Journal of The Royal Society Interface, v.15, 2018.

VON WIRÉN-LEHR, S. Sustainability in Agriculture - an Evaluation of Principal Goal-Oriented Concepts to Close the Gap between Theory and Practice. Agriculture, Ecosystems \& Environment, v84, n2, 2001. Disponível em: http://dx.doi. org/10.1016/S0167-8809(00)00197-3 Acesso em: maio 2020.

WONG, A. et al. Global Epidemiology of Bat Coronaviruses. Viruses, v.11, 2019.

XIAO, K. et al. Isolation and Characterization of 2019-nCoV-like Coronavirus from Malayan Pangolins. Cold Spring Harbor Laboratory, 2020.

ZHANG, T. et al. Probable Pangolin Origin of SARS-CoV-2 Associated with the COVID-19 Outbreak. Current Biology, v.30, 2020.

ZHOU, P. et al. A Pneumonia Outbreak Associated with a New Coronavirus of Probable Bat Origin. Nature, v.579, 2020.

ZOHDY, S. et al. The Coevolution Effect as a Driver of Spillover. Trends in Parasitology, v.35, 2019.

RESUMO - O atual formato de desenvolvimento humano gera severos impactos ambientais, os quais repercutem negativamente na saúde; dentre eles, a intensificação da transmissão de doenças infecciosas, epidemias e pandemias, como a Covid-19. A forma como lidamos com a biodiversidade e os ecossistemas, em conjunto com as mudanças climáticas, viabiliza interfaces e corredores por onde ocorrem diversificação, spillover e circulação de vírus. Por esses meios, o Sars-CoV-2 poderá invadir biomas brasileiros, transformando florestas como a Amazônia em imensos reservatórios, de onde o coronavírus poderá retornar ainda mais agressivo à saúde.

PALAVRAS-CHAVE: Pandemia do coronavírus, Covid-19, Sars-CoV, Biodiversidade e ecossistemas, Saúde planetária.

ABSTRACT - The current path of human development generates deleterious environmental impacts, which have negative impact on health; among them, intensified transmission of infectious diseases, epidemics and pandemics, such as covid-19. The way we usually deal with biodiversity and ecosystems, combined with the effects of climate change, make for interfaces and pathways that favor diversification, spillover and the circulation of viruses. By these means, Sars-CoV-2 may invade Brazilian biomes, transforming, for instance, the Amazon rain forest into a huge reservoir from where coronavirus may return even more aggressive to health.

KErWORDS: Coronavirus pandemic, Covid-19, Sars-CoV-2, Biodiversity \& ecosystems, Planetary health.

Andre Luis Acosta é doutor em Ecologia pela Universidade de São Paulo, post-doc. na Faculdade de Saúde Pública (USP), pesquisador no Centro Brasil-Reino Unido de Descoberta, Diagnóstico, Genômica e Epidemiologia de Arbovírus, membro do Grupo de Estudos em Saúde Planetária do Instituto de Estudos Avançados da USP. @ - andreluisacosta@gmail.com / https://orcid.org/0000-0002-4244-9637. 
Fernando Xavier é doutorando em Engenharia de Computação pela Escola Politécnica da Universidade de São Paulo, pesquisador do Grupo de Estudos em Saúde Planetária do Instituto de Estudos Avançados da USP. @ - fxavier@usp.br / https://orcid.org/0000-0001-5797-7339.

Leonardo Suveges Moreira Chaves e doutor Saúde Pública pela Faculdade de Saúde Pública da Universidade de São Paulo (FSP-USP). @ - leonardosuveges@usp.br / https://orcid.org/0000-0002-7632-1842.

Ester Cerdeira Sabino é doutora em Imunologia e professora do Departamento de Moléstias Infecciosas na Faculdade de Medicina da Universidade de São Paulo, coordenadora do Centro Brasil-Reino Unido de Descoberta, Diagnóstico, Genômica e Epidemiologia de Arbovírus, membro do Grupo de Estudos em Saúde Planetária do Instituto de Estudos Avançados da USP. @ - sabinoec@gmail.com / https://orcid.org/0000-0003-2623-5126.

Antonio Mauro Saraiva é doutor em Engenharia de Computação e professor da Escola Politécnica da Universidade de São Paulo e coordenador do Grupo de Estudos em Saúde Planetária do Instituto de Estudos Avançados da USP. @ - saraiva@usp.br / https://orcid.org/0000-0003-2283-1123.

Maria Anice Mureb Sallum é doutora em Saúde Pública e professora do Departamento de Epidemiologia da Faculdade de Saúde Pública da USP, participa do projeto Centro Brasil-Reino Unido de Descoberta, Diagnóstico, Genômica e Epidemiologia de Arbovírus e membro do Grupo de Estudos em Saúde Planetária do Instituto de Estudos Avançados da USP. @ - masallum@usp.br / http://orcid.org/0000-0002-7051-2891.

Recebido em 25.5.2020 e aceito em 19.6.2020.

I, II, IV, VI Instituto de Estudos Avançados, Universidade de Sâo Paulo, São Paulo, Brasil.

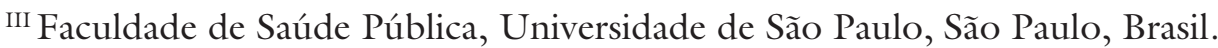

${ }^{v}$ Escola Politécnica, Universidade de São Paulo, São Paulo, Brasil. 
